\title{
Isabelle comBÈs, Una etnohistoria del Chaco boliviano
}

\section{Cecilia Martínez}

\section{(2) OpenEdition Journals}

\section{Edición electrónica}

URL: https://journals.openedition.org/jsa/19749

DOI: 10.4000/jsa. 19749

ISSN: 1957-7842

\section{Editor}

Société des américanistes

\section{Edición impresa}

Fecha de publicación: 30 septiembre 2021

Paginación: 265-270

ISSN: 0037-9174

\section{Referencia electrónica}

Cecilia Martínez, «Isabelle combès, Una etnohistoria del Chaco boliviano», Journal de la Société des américanistes [En línea], 107-1 | 2021, Publicado el 30 septiembre 2021, consultado el 02 septiembre 2022. URL: http://journals.openedition.org/jsa/19749 ; DOI: https://doi.org/10.4000/jsa. 19749

Este documento fue generado automáticamente el 2 septiembre 2022.

All rights reserved 


\title{
Isabelle comBÈs, Una etnohistoria del Chaco boliviano
}

\author{
Cecilia Martínez
}

\section{REFERENCIA}

Isabelle comвÈs, Una etnohistoria del Chaco boliviano, El País (Ciencias Sociales e Historia, 49), Santa Cruz de la Sierra, 2021, 268 p., bibliogr., índice de etnónimos y lenguas, ill. (en blanco y negro), mapas, tabl.

De todas las formas posibles de abordar a los indígenas del Chaco, la que Isabelle Combès despliega en este libro es la menos frecuente, y en ella reside su más destacado y original aporte. Una etnohistoria del Chaco boliviano propone una perspectiva diacrónica y regional para estudiar a grupos indígenas que mayoritariamente fueron considerados en su dimensión sincrónica y monográfica: ahí donde la tradición etnológica destacó aspectos lingüísticos, sociopolíticos, socioculturales y simbólicos que diferencian a los grupos chaqueños entre sí y que, en conjunto, distinguen a un indígena chaqueño "típico", Isabelle Combès aporta en cambio una mirada histórica y una perspectiva relacional especialmente atenta a la formación y transformación de esos grupos. Así, al mismo tiempo que se posa sobre los hombros del gigante que constituye aquella tradición, alcanza una profundidad analítica que en parte la complementa y en parte la cuestiona. Como consecuencia de ese contrapunto, no es un recorte por etnias ni la descripción de sus formas de vida, creencias y organización política lo que se encuentra en estas páginas, sino un análisis etnohistórico, cronológica y geográficamente ordenado de la evidencia sobre los indígenas chaqueños desde el siglo xvi hasta la posguerra del Chaco, en el que lo "etnohistórico" no es una mera enumeración de acontecimientos indígenas, ni tampoco una reconstrucción de la concepción indígena del pasado. La etnohistoria que se narra aquí es la que emerge de las relaciones interétnicas a lo largo de esos siglos: la de la interacción de los distintos grupos entre sí y con actores no indígenas, la de su 
movimiento en el territorio, la de sus cambios y reconfiguraciones; en suma, la historia social de los indígenas del Chaco boliviano.

2 Esta perspectiva etnohistórica, aunque inusual, no es novedosa. Los trabajos de Branislava Susnik son, en efecto, el antecedente que, de manera explícita, Isabelle Combès continúa en su obra. Pero, además, la propia autora ha sabido cultivar y amplificar esta perspectiva analítica en sus investigaciones durante los últimos veinte años. En las páginas de este libro resuena el contenido de previos artículos suyos como "Susnik y los gorgotoquis..." (2012), "Los fugitivos escondidos..." (2008), "De Sanandita a Itiyuro..." (2007), o de libros como Zamucos (2009) o Etno-historias del Isoso (2005). Lo novedoso es que la etnohistoria de este libro ensambla esas piezas monográficas en una síntesis regional que integra las dinámicas de unos indígenas con las de otros. El resultado es una imagen del Chaco indígena boliviano en la que termina siendo evidente que todos los pueblos autóctonos estaban interconectados entre sí y que, por lo tanto, los movimientos o transformaciones de uno repercutían de manera directa o diferida sobre los de los demás. Esto, que suena tanto a "Verdad de Perogrullo" (así se titula la introducción al libro) como decir que "los indígenas tienen historia [y que] el Chaco indígena tiene historia" (p.13) es, sin embargo, el punto de partida de un señalamiento que recorre todo el libro: el cuestionamiento de la idea de que los indígenas del Chaco, por haber sido por mucho tiempo refractarios a la colonización, no tenían historia, y que por no tenerla vivían en una suerte de inmovilidad geográfica y de perennidad sociopolítica y sociocultural.

3 Sin embargo, la ausencia de colonización no implica ausencia de contacto. Uno de los pilares de esta etnohistoria es, justamente, el análisis de evidencia histórica que proviene de agentes que rodearon el Chaco con el objetivo de explorarlo, franquearlo, delimitarlo, contenerlo o colonizarlo. Por eso, este relato también es la "historia en negativo" de los intentos por mucho tiempo frustrados de exploradores, funcionarios y militares de ocupar el Chaco boreal. Un sobrevuelo de ese derrotero exploratorio del largo período que abarca el libro es materia del primer capítulo, "Noticias periféricas". Allí la autora se refiere a las expediciones pioneras desde el este y el norte, que fueron los intentos del arco conquistador rioplatense de llegar a los Andes en el siglo XVI, y también a las incursiones colonizadoras y punitivas desde Charcas contra los chiriguanos. El siglo XVIII es luego el siglo de la evidencia misionera, desde el norte con los jesuitas de Chiquitos que se internan en la tierra de los zamucos, y desde el oeste con los franciscanos de Tarija y su intento de pacificar a los chiriguanos. Otras misiones entre tobas y noctenes en el siglo xix se acoplan al impulso secular de las compañías de colonización en el Oriente boliviano y de las exploraciones patrocinadas por el Estado boliviano, que avanzan a paso firme desde el oeste y desde el sur en busca de una salida fluvial por los ríos Paraguay y Pilcomayo. De a poco, con ayuda de la actividad ganadera, van corriendo progresivamente hacia el interior del Chaco la línea que las separa de los indígenas. Entonces los datos se vuelven cada vez más precisos. En el siglo xx, las etnografías de Alfred Métraux, Erland Nordenskiöld o Rafael Karsten desde el sur y desde el oeste de la región se complementan con la evidencia que dejó una política activa de afirmación de la presencia de Bolivia en la frontera, que luego desembocaría en la Guerra del Chaco.

4 A continuación de este primer capítulo introductorio, la exposición sigue los ritmos de la evidencia y se divide en otros cuatro capítulos que remiten a los distintos frentes en la periferia, desde donde puede mirarse el Chaco: occidental, norte, sur, y todos los frentes. En "Desde el frente oeste" (capítulo 2), se presenta a los chanés como protagonistas del 
intenso tráfico precolombino de metales. Junto con la migración guaraní desde el Alto Paraguay al piedemonte andino, permiten dar cuenta de un panorama precolombino y temprano-colonial por demás dinámico que no tarda en mostrar sus efectos etnogenéticos: la aparición de los chiriguanos primero, producto de su imposición sobre los chanés, y luego de los fugitivos del yugo chiriguano que encuentran Chaco adentro una zona de refugio.

5 "Desde el frente norte" (capítulo 3) hace foco en la "efervescencia étnica"1 precolombina desde el ángulo chiquitano. A partir del paradigmático caso de los gorgotoquis, devenidos penoquis ${ }^{2}$ dos siglos después, dos grandes problemas de la etnografía clásica del Chaco surgen en toda su complejidad: el de los etnónimos y el de la pretendida correspondencia entre lengua y cultura. Además, este frente norte -frente de la osadía jesuítica que llegó a fundar una misión en el interior más septentrional del Chaco- nos muestra la diversidad de grupos zamuco-hablantes y con ella un clivaje antiguo de grupos y parcialidades que anticipa la distinción contemporánea entre ayoreos e ishir.

6 En "Desde el frente sur" (capítulo 4) volvemos a encontrarnos con los chiriguanos, aunque esta vez aliados con grupos tobas y matacos contra las misiones franciscanas, y contra bandeirantes portugueses que amenazan con esclavizarlos desde el este en el siglo XVIII. A medida que avanzan las exploraciones y el frente colonizador en el siglo XIX, los conflictos y las alianzas se intensifican, al mismo tiempo que se amplía el conocimiento sobre los indígenas del alto Pilcomayo chaqueño y aparecen guisnais, noctenes o matacos, tapietes, chorotes, tobas, a veces de primera mano por parte de exploradores, otras veces mediados por los chiriguanos de las misiones franciscanas. Pero cuando los chiriguanos sean doblegados en el último cuarto del siglo y se integren en haciendas, migren a los ingenios del norte argentino, o busquen refugio entre los tapietes que antes habían huido de ellos, quedarán al descubierto grupos del interior chaqueño tobas, weenhayek, chorotes y tapietes de los que -por mucho tiempo- solo se había tenido noticias diferidas.

7 "Desde todos los frentes" (capítulo 5), por fin, es la síntesis de la estocada final al refugio que el Chaco supo ser para sus habitantes indígenas. Buscando aventajarse en la disputa con Paraguay, la política boliviana de ocupación del territorio incluyó secularización de misiones, establecimiento de fortines y apertura de caminos, y engrosó los grupos de fugitivos acelerando la fricción entre los que ya estaban y los que llegaban para arrinconarse en el corazón chaqueño. Una guerra cruenta entre tsirakua (zamucos) y tapietes no demora en desatarse, al tiempo que la confederación zamuco de los guidaygosode se enfrenta con grupos pequeños, también zamucos, que huyen a Chiquitos. Finalmente, la guerra se cierne sobre el Chaco. El epílogo proyecta de forma somera la situación de los indígenas chaqueños hasta la actualidad luego del conflicto bélico y de la colonización del Chaco, en la que predominan problemáticas propias ya no de las relaciones interétnicas entre los distintos grupos, sino de su integración con la sociedad blanca.

8 Así, el relato completo de esta etnohistoria que propone Isabelle Combès dibuja una espiral desde los bordes hacia el interior del Chaco, desde lo más antiguo a lo más reciente, pasando varias veces por el mismo lugar que, en un tiempo distinto, ya no es el mismo. La autora presenta y analiza la información sobre los indígenas en distintas épocas, y se concentra en las continuidades, las interrupciones, las transformaciones y los solapamientos en los que la etnonimia ocupa un lugar destacado. El problema de los nombres indígenas es recurrente como guía metodológica, pero también como recurso 
heurístico y, no menos importante, como supuesto teórico. El análisis de los nombres remite a la perspectiva relacional y, por lo tanto, a las dinámicas interétnicas ponderadas por la autora. En virtud de ella considera las condiciones de posibilidad del discurso sobre los indígenas disponible en la evidencia histórica, es decir, el contexto de registro, los interlocutores, los referentes, los sentidos y los significados. Los etnónimos que a lo largo de este tiempo fueron atribuidos a los distintos grupos chaqueños no son otra cosa que el reflejo de las relaciones que estos establecieron entre sí y con los no indígenas. Las designaciones de origen guaraní, muchas veces despectivas, dan cuenta de la mediación entre los grupos del interior del Chaco con los conquistadores y colonizadores por parte de los itatines desde el río Paraguay primero y de los chiriguanos luego a partir del piedemonte andino. Términos como tapii, tapiete, yanaigua e itirumbae ${ }^{3}$ evocan entonces una autopercepción superlativa y un tipo de vínculo con los grupos del interior del Chaco que es producto de ella. De manera similar, aunque no necesariamente como marca de superioridad, pero tal vez sí de la tan referida "dependencia directa socioperiférica" que propusiera Susnik (1981, p.161), parecen haber funcionado para chanés y chiquitos los nombres tamúcu o tamokosh ${ }^{4}$, devenidos luego zamuco y más tarde chamacoco. En el mismo orden de cosas relativas a los nombres y a las lenguas, la frecuencia elevada del sufijo -ono (plural de las lenguas arawak meridionales) que encontramos en los nombres relevados en el siglo XVI en el borde septentrional del Chaco por los conquistadores de Santa Cruz nos revela la evidente centralidad de los chanés y de otros grupos arawak-hablantes no solo en el tráfico de objetos de metal sino en la integración de la diversidad de los grupos humanos que vivían allí o frecuentaban la región. A diferencia del tratamiento del factor lingüístico en la tradición etnográfica y etnológica del Chaco, que suele inscribirla en un correlato indisoluble con una sociedad y con una cultura determinadas, la lengua indígena aparece aquí no como conclusión, sino como punto de partida y siempre como correlato de una relación social y, por lo tanto, como un elemento dinámico. Esta flexibilidad analítica e interpretativa -producto del estudio de la evidencia en dimensión diacrónica- resulta en un fuerte cuestionamiento de la existencia de un indígena chaqueño "típico", afirmada por la etnología tradicional, asociado con determinadas familias lingüísticas, con manifestaciones minimalistas de cultura material y con formas simples de organización social. Los contraejemplos de los zamucos, cazadores-recolectores con una compleja organización social en clanes, tal vez producto de su contacto con grupos otuqui; de los tapietes, cazadores recolectores hablantes del guaraní, lengua asociada con la agricultura como medio de subsistencia y forma de vida; o de los chanés y los chiriguanos, agricultores de los que difícilmente podría afirmarse que no son indígenas del Chaco, nos invitan a repensar al indígena de esta región como un haz de posibilidades históricamente determinadas antes que como un tipo único.

Quisiera finalizar con una digresión historiográfica para señalar otro aporte no menos importante que los que mencioné, no solo por su contenido en sí sino por la invitación implícita a los historiadores para realizar una lectura del campo de la historia popular o de los sectores populares. Al pasar revista rápida de la historiografía del Chaco, se advierte que esta región muchas veces despertó el interés de los historiadores a propósito del conflicto que tuvo lugar entre 1932 y 1935. Diría que, incluso cuando fue abordada desde miradas diversas como las del derecho y las relaciones internacionales, la economía o la política nacional boliviana, la historiografía del Chaco se encuentra notablemente ceñida al conflicto entre Bolivia y Paraguay. Hasta las investigaciones que procuraron abarcar una mayor profundidad temporal lo hicieron con el objetivo de 
explicar mejor la génesis del conflicto o los fundamentos de cada contendiente para reclamar su derecho de soberanía sobre el Chaco boreal. A la luz de ese estado del arte historiográfico, este libro muestra cómo se puede, al decir de Walter Benjamin, "pasarle a la historia el cepillo a contrapelo" al combinar etnología y sentido histórico en la misma mirada analítica. El resultado es una etnohistoria que pone en evidencia una profundidad diacrónica pocas veces reconocida para el Chaco boliviano, que es nada menos que la de los indígenas que lo habitaron y que aún lo habitan.

\section{BIBLIOGRAFÍA}

COMBÈs Isabelle

2005 Etno-historias del Isoso. Chané y chiriguanos en el Chaco boliviano (siglos XVI a XX), Fundación PIEB/Instituto Francés de Estudios Andinos, La Paz.

COMBÈs Isabelle

2007 "De Sanandita a Itiyuro: los chanés, los chiriguanos (¿y los tapietes?) al sur del Pilcomayo", Indiana, 24, p. 259-289.

comBÈs Isabelle

2008 "Los fugitivos escondidos: acerca del enigma tapiete", Bulletin de l'Institut français d'études andines, 37 (3), p. 511-533.

COMBÈs Isabelle

2009 Zamucos, Instituto de Misionología, Cochabamba.

coMBÈs Isabelle

2012 "Susnik y los gorgotoquis. Efervescencia étnica en la Chiquitania (Oriente boliviano)", Indiana, 29, p. 201-220.

SUS: NIK Branislava

1978 Los aborígenes del Paraguay. I. Etnología del Chaco boreal y su periferia (siglos XVI y XVII), Museo etnográfico Andrés Barbero, Asunción.

SUS:NIK Branislava

1981 Los aborígenes del Paraguay. III/1. Etnohistoria de los chaqueños (1650-1910), Museo etnográfico Andrés Barbero, Asunción.

\section{NOTAS}

1. "Efervescencia étnica" es la caracterización que propuso Branislava Susnik (1978, p. 45) para referirse al dinamismo étnico del Chaco boreal y su periferia en el momento previo a la llegada de los primeros exploradores españoles.

2. El nombre "gorgotoqui", muy presente en el límite septentrional del Chaco en el siglo xVI, ya no aparece en la evidencia jesuítica del siglo xVIII. En cambio, un nuevo nombre prevalece: penoqui o penoquica. Si bien fueron considerados chiquito-hablantes, 
estos penoqui del siglo XVIII se distinguían de los demás por su dialecto homónimo, peculiar y exclusivo. Además, vivían en los alrededores del pueblo de San José; es decir, a escasos dos kilómetros de la abandonada Santa Cruz la Vieja donde se radicaban los gorgotoqui.

3. Se trata en todos los casos de términos en guaraní: tapii significa "esclavo" y era la forma en que los chiriguanos designaban a los chanés; los tapiete son "los verdaderos esclavos", designación también aplicada a los chanés; los yanaigua son por su parte "los que viven en el monte", término genérico de distintos grupos guaraní-hablantes para referirse a sus vecinos, también llamados itirumbae, "los que no usan tiru", siendo el tiru la vestimenta tradicional de los hombres chiriguanos.

4. Ambos términos significan "perro", y el sentido del uso del término se entiende a partir de estudios etnográficos que examinaron el lugar de los perros en sociedades chaqueñas (p. 110).

\section{AUTORES}

CECILIA MARTÍNEZ

IICS-Conicet/UCA 